\title{
Enthalpy of Mixing of Ternary Li-Pb-Sb Alloys
}

\author{
Sylwia Terlicka ${ }^{1} \cdot$ Adam Dębski $^{1} \cdot$ Przemyslaw Fima $^{1}$ (D)
}

Submitted: 23 March 2018/in revised form: 15 June 2018/Published online: 28 June 2018

(C) The Author(s) 2018

\begin{abstract}
Partial and integral enthalpies of mixing of ternary $\mathrm{Li}-\mathrm{Pb}$-Sb alloys were measured at 923 and $1023 \mathrm{~K}$ with drop calorimetry. In total 12 sections were studied of fixed molar ratios of $\mathrm{Li}$ to $\mathrm{Pb}$ equal to $1 / 9,1 / 3,2 / 3,1,3 / 2$, $3, \mathrm{~Pb}$ to $\mathrm{Sb}$ equal to $3 / 1,1,1 / 3$ and $\mathrm{Li}$ to $\mathrm{Sb}$ equal to $1 / 4$, $2 / 3,1$. The measurements were performed by consecutive dropping solid metal samples $(\mathrm{Li}, \mathrm{Pb}$ or $\mathrm{Sb})$ from ambient temperature into calorimeter chamber. In the first step calibration was performed, in the second binary starting alloy was formed, and finally enthalpies of liquid ternary alloys were measured. Integral enthalpies of mixing are negative in the whole concentration range studied, and tend to a minimum associated with a minimum in $\mathrm{Li}-\mathrm{Sb}$ system.
\end{abstract}

Keywords calorimetry $\cdot$ enthalpies of mixing $\cdot \mathrm{Li}-\mathrm{Pb}-\mathrm{Sb}$ alloys $\cdot$ thermodynamic properties

\section{Introduction}

Novel rechargeable liquid metal batteries (LMB), invented in 2009 by MIT research group led by Donald Sadoway, ${ }^{[1-3]}$ where both electrodes and electrolyte are in a liquid form, have an ability to store a large amount of electricity from renewable energy sources such as wind or solar, and to deliver this electricity when it is required. Wang et al. ${ }^{[3]}$ proposed the $\mathrm{Li}-\mathrm{Pb}-\mathrm{Sb}$ alloys as a potential electrode candidate for LMB technology, due to relatively

Przemyslaw Fima

p.fima@imim.pl

1 Institute of Metallurgy and Materials Science, Polish Academy of Sciences, ul. Reymonta 25, 30-059 Krakow, Poland high cell voltage (about $0.9 \mathrm{~V}$ open-circuit voltage), low self-discharge and long-term stability. However, phase relations in the $\mathrm{Li}-\mathrm{Pb}-\mathrm{Sb}$ system and thermodynamic data for constituent phases has not yet been reported. High temperature drop calorimetry readily provides partial and integral enthalpies of mixing, which may be further used to develop a thermodynamic description of the liquid phase in the $\mathrm{Li}-\mathrm{Pb}-\mathrm{Sb}$ system. Therefore the aim of this work is to measure enthalpies of mixing in liquid $\mathrm{Li}-\mathrm{Pb}-\mathrm{Sb}$ alloys.

Although there are no reports on thermodynamic properties of liquid $\mathrm{Li}-\mathrm{Pb}-\mathrm{Sb}$ alloys, the enthalpies of mixing of constituent binary alloys are well studied. Integral enthalpies of mixing of liquid $\mathrm{Pb}-\mathrm{Sb}$ alloys were studied by many, as summarized by Gierlotka et al. ${ }^{[4]}$ All of the reported integral enthalpies are close to zero and thermodynamic properties of liquid $\mathrm{Pb}-\mathrm{Sb}$ alloys only slightly deviate from ideal solution. ${ }^{[4]}$ Integral enthalpies of mixing of $\mathrm{Li}-\mathrm{Pb}$ alloys at $1000 \mathrm{~K}$ reported in Ref 5 are negative in the whole concentration range with a minimum of $\sim-29 \mathrm{~kJ} / \mathrm{mol}$ at $0.25 \mathrm{~mol}$ fraction $\mathrm{Pb}$. Recent measurements of integral enthalpies carried out at between 817 and $1023 \mathrm{~K},{ }^{[6]}$ are close to Ref 5 and indicate that the integral enthalpies of mixing of liquid $\mathrm{Li}-\mathrm{Pb}$ alloys are temperature independent. Enthalpies of mixing of liquid Li-Sb alloys were measured calorimetrically by the present authors at $922 \mathrm{~K}$ over $0.46-0.87 \mathrm{~mol}$ fraction $\mathrm{Sb}^{[7]}$ These were recently confirmed experimentally by Li et al. ${ }^{[8]}$ over $\mathrm{Sb}$ concentration range $0.43-0.97 \mathrm{~mol}$ fraction $\mathrm{Sb}$ at 929 and $979 \mathrm{~K}$. According to both sets of data, ${ }^{[7,8]}$ integral enthalpies of mixing do not show temperature dependency and, in the concentration range studied, decrease with decreasing content of $\mathrm{Sb}$ to reach $\sim-55 \mathrm{~kJ} / \mathrm{mol}$ at $0.44 \mathrm{~mol}$ fraction of $\mathrm{Sb}$. 


\section{Materials and Method}

All of the substances used in present study, without further purification, are listed in Table 1. All measurements were carried out with the use of the Setaram MHTC 96 Line Evo calorimeter under the protective atmosphere of high purity argon. This calorimeter has a thermopile constructed of 20 thermocouples, graphite tube resistance furnace, and manual drop device in which each piece of metal is loaded separately, evacuated and flushed with argon before being dropped to the calorimeter chamber. The drop device has detachable antechamber allowing transfer of Li pieces from argon filled glovebox. The liquid alloys, in all measurements, were held in tungsten crucibles (internal dimensions: $69 \mathrm{~mm} \times 7.6 \mathrm{~mm}$ in dia.) because $\mathrm{W}$ neither dissolves nor reacts with $\mathrm{Sb} .{ }^{[9]}$ Crucibles could be reused after their content was removed by dissolving in nitric acid. Before running of each experiment and dropping samples, the calorimeter was evacuated several times by a rotary vacuum pump, and flushed with high purity argon. At the beginning of each experiment, after stabilising the temperature and the baseline (more than $3 \mathrm{~h}$ from the start of heating and before the first drop), the calibration constant was determined by dropping the six calibration pieces of $\mathrm{Li}, \mathrm{Pb}$ or $\mathrm{Sb}$ (depending on the starting ratio of $\mathrm{Li}$ to $\mathrm{Pb}, \mathrm{Pb}$ to $\mathrm{Sb}$, or $\mathrm{Li}$ to $\mathrm{Sb}$,). Once calibration was completed, appropriate amount of the second component (in a single piece) was dropped to the calorimeter to form the binary starting alloy of respective $\mathrm{Li}$ to $\mathrm{Pb}, \mathrm{Li}$ to $\mathrm{Sb}$ and $\mathrm{Pb}$ to $\mathrm{Sb}$ molar ratio. Then, the main experiments were started, when the pieces of third component were dropped to the liquid binary alloys in the crucible. The voltage signal from the thermopile was registered in a digital form, and then the heat effects and the mixing enthalpies were calculated according to Eq 1-4. The heat effects were measured up to the moment when the baseline achieved the same constant value as that before the reaction (in average about $40 \mathrm{~min}$ per drop). Due to the high reactivity of Li with air components such as nitrogen, oxygen, carbon dioxide or water vapor, the $\mathrm{Li}$ pieces were prepared and locked in calorimetric antechamber inside the glove box in a high purity argon atmosphere with trace amounts of moisture, $\mathrm{O}_{2}$ and

Table 1 Substances used in present study, purity as certified by suppliers

\begin{tabular}{llc}
\hline Chemical name & Source & Purity (mass.\%) \\
\hline Lead & Alfa Aesar & 99.9999 \\
Lithium & Alfa Aesar & 99.9 \\
Antimony & Alfa Aesar & 99.99 \\
Argon & Air products & 99.9999 \\
\hline
\end{tabular}

nitrogen. Then, this antechamber was removed from the glovebox, and connected to the calorimeter.

Integral enthalpies of mixing for binary $\mathrm{Pb}-\mathrm{Sb}$ alloys, needed as a starting point for ternary enthalpy determination, were calculated from the thermodynamic description of the liquid phase of $\mathrm{Pb}-\mathrm{Sb}$ system. ${ }^{[4]}$ Integral enthalpies of binary $\mathrm{Li}-\mathrm{Pb}$ alloys were directly taken from the recent paper, ${ }^{[6]}$ whereas integral enthalpies of $\mathrm{Li}-\mathrm{Sb}$ alloys were determined in this work and found to be consistent with those published earlier. ${ }^{[7,8]}$ Then enthalpies of ternary alloys were measured along 12 sections of fixed molar ratios of $\mathrm{Li}$ to $\mathrm{Pb}$ equal to $1 / 9,1 / 3,2 / 3,1,3 / 2,3, \mathrm{~Pb}$ to $\mathrm{Sb}$ equal to $3 / 1,1,1 / 3$ and $\mathrm{Li}$ to $\mathrm{Sb}$ equal to $1 / 4,2 / 3,1$, as illustrated in Fig. 1. Measurements were performed at $923 \mathrm{~K}$, except for sections of $\mathrm{Li}$ to $\mathrm{Pb}$ equal to 3, 3/2 where measurement temperature was $1023 \mathrm{~K}$.

The integral and partial enthalpies of mixing $\left(\Delta_{\text {mix }} H\right.$, $\left.\Delta H_{\mathrm{X}}\right)$ of the Li-Pb-Sb liquid alloys can be described using the equations listed below:

$H_{\text {DISS }-\mathrm{X}}=\left(\Delta H_{\text {Signal }} \cdot K\right)-\left(H_{\mathrm{X}}^{\mathrm{T}_{\mathrm{R}} \rightarrow \mathrm{T}_{\mathrm{M}}} \cdot n_{\mathrm{X}}\right)$

$K=\frac{H_{\mathrm{x}}^{T_{\mathrm{R}} \rightarrow T_{\mathrm{M}}} \cdot \mathrm{n}_{\mathrm{X}}}{\Delta H_{\text {Calibration }}}$

$\Delta_{\text {mix }} H=\frac{\sum H_{\text {DISS }-\mathrm{X}}}{n \mathrm{j}+\sum n_{\mathrm{X}}}$

$\Delta H_{\mathrm{x}}=\frac{H_{\mathrm{DISS}-\mathrm{X}}}{n_{\mathrm{x}}}$

where $\Delta H_{\text {Signal }}$ is the heat effect of each dropped metal ( $\mathrm{Li}$, $\mathrm{Pb}$ or $\mathrm{Sb}$ ) which equalled the added drop enthalpy; $\mathrm{K}$ is the

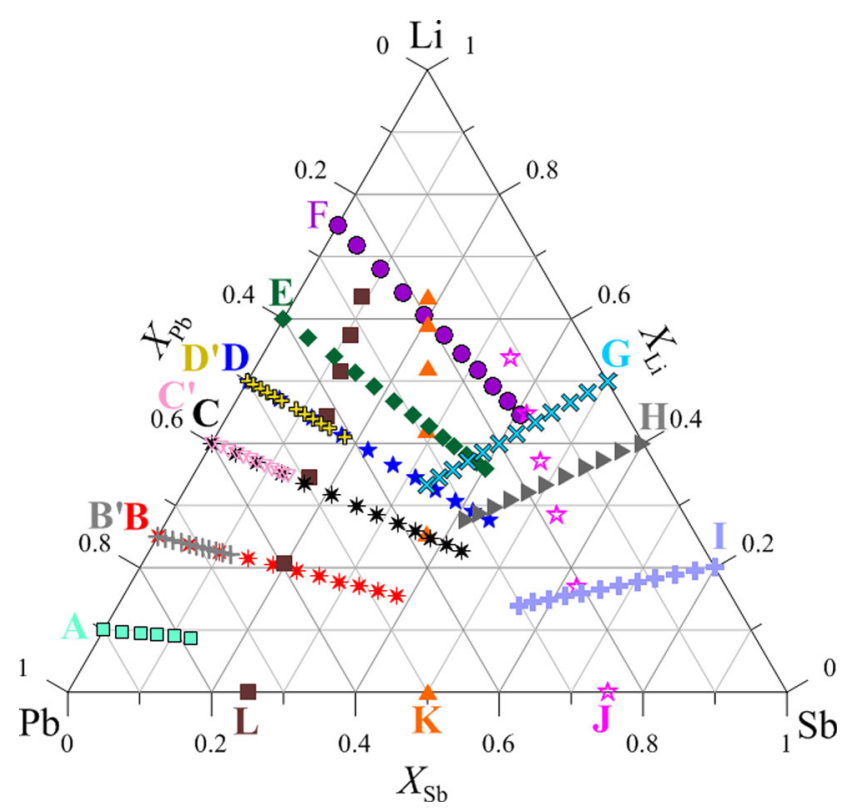

Fig. 1 The points corresponding to measured compositions of alloys of the Li-Pb-Sb system 
calorimeter constant; $\Delta H_{\mathrm{X}}^{\mathrm{T}_{\mathrm{R}} \rightarrow \mathrm{T}_{\mathrm{M}}}$ is the molar enthalpy difference of $\mathrm{X}$ pure element $(\mathrm{X}=\mathrm{Li}, \mathrm{Pb}, \mathrm{Sb})$ between room temperature $\left(T_{\mathrm{R}}=298 \mathrm{~K}\right)$ and temperature of measurement $\left(T_{\mathrm{M}}\right)$, calculated using SGTE v4.4 database; ${ }^{[10]} n_{\mathrm{X}}$ $\left(n_{\mathrm{Li}}, n_{\mathrm{Pb}}, n_{\mathrm{Sb}}\right)$ are the number of moles of lithium, lead and antimony, respectively; $H_{\text {DISS-X }}$ is the enthalpy of dissolution of pure lithium, lead or antimony; $n_{\mathrm{j}}$ is a number of moles of components in the crucible before the starting of the main integral molar mixing enthalpy measurements; $\Delta H_{\text {Calibration }}$ is the heat effect of dropped metal, which was used for calibration.

\section{Results and Discussion}

Tables 2, 3, and 4 contain partial and integral enthalpies of mixing of $\mathrm{Li}-\mathrm{Pb}-\mathrm{Sb}$ alloys, together with all the experimental information needed i.e. temperatures, starting amounts, dropped amounts, the corresponding heat effects, enthalpies of dropped components calculated using SGTE data, ${ }^{[10]}$ and binary starting points of the integral enthalpy of mixing. Integral enthalpies of mixing are graphically presented in Fig. 2(a)-(c).

Starting from the $\mathrm{Li}-\mathrm{Pb}$ side (sections A-F) the enthalpies were measured up to $\sim 0.45 \mathrm{~mol}$ fraction $\mathrm{Sb}$, from $\mathrm{Li}-\mathrm{Sb}$ side (sections G-I) up to $\sim 0.3$ mol fraction of $\mathrm{Pb}$, and from $\mathrm{Pb}-\mathrm{Sb}$ side (sections $\mathrm{J}-\mathrm{L}$ ) up to $\sim 0.6 \mathrm{~mol}$ fraction $\mathrm{Li}$. The integral enthalpies of mixing in the $\mathrm{Li}-\mathrm{Pb}-\mathrm{Sb}$ system are negative in the whole concentration range studied, and strongly depend on concentration. In the case of enthalpies measured from $\mathrm{Li}-\mathrm{Pb}$ (sections $\mathrm{A}-\mathrm{F}$ ) and $\mathrm{Li}$ $\mathrm{Sb}$ (sections G-I) side, the integral enthalpies are lower for starting binary alloys, which contain more lithium. As illustrated in Fig. 2(a), integral enthalpies measured from the $\mathrm{Li}-\mathrm{Pb}$ side for each experimental section decrease initially until they reach a minimum, then further increase with increasing Sb concentration. For sections B, C, D two individual measurement series were performed, the second with smaller concentration step, and the results were repeatable. As the $\mathrm{Li}$ to $\mathrm{Pb}$ molar ratio increases in the series A-F, the integral enthalpies are lower, the minima get deeper and shift towards higher Sb concentrations. For example, in section $\mathrm{B}$ ( $\mathrm{Li}$ to $\mathrm{Pb}$ ratio equal to $1 / 3$ ) the minimum of integral mixing enthalpy $(\sim-23 \mathrm{~kJ} / \mathrm{mol})$ occurs at 0.08 mol fractions $\mathrm{Sb}$. In the case of section $\mathrm{F}$ ( $\mathrm{Li}$ to $\mathrm{Pb}$ ratio equal to 3 ) the minimum of integral mixing enthalpy $(\sim-62 \mathrm{~kJ} / \mathrm{mol})$ corresponds to $0.19 \mathrm{~mol} \mathrm{frac}-$ tion of $\mathrm{Sb}$. Integral enthalpies measured from the $\mathrm{Pb}-\mathrm{Sb}$ (Fig. 2c) side decrease with increasing concentration of $\mathrm{Li}$, in the concentration range studied, only for section $\mathrm{L}(\mathrm{Pb}$ to $\mathrm{Sb}$ molar ratio 3) the minimum is observed at $\sim 0.55 \mathrm{~mol}$ fraction Li. Since the difference between enthalpy values for starting points on the $\mathrm{Pb}-\mathrm{Sb}$ side is negligible, there are no significant differences between sections of different $\mathrm{Pb}$ to $\mathrm{Sb}$ ratio. The decreasing trend in integral enthalpies of mixing measured by dropping $\mathrm{Li}$ from $\mathrm{Pb}-\mathrm{Sb}$ (Fig. 2c) side strongly resembles the trend of integral enthalpies in liquid $\mathrm{Li}-\mathrm{Sb}$ alloys measured from the Sb side. ${ }^{[7,8]}$ On the other hand, integral enthalpies of mixing measured by dropping $\mathrm{Pb}$ from the $\mathrm{Li}-\mathrm{Sb}$ side (Fig. 2b) do not show similar behaviour, instead they increase nearly monotonically with increasing $\mathrm{Pb}$ concentration.

In Table 5, integral enthalpies of mixing measured near the points of intersection of experimental sections are compared. The greatest difference is observed between sections $\mathrm{J}$ and $\mathrm{F}(5.6 \mathrm{~kJ} / \mathrm{mol})$, and $\mathrm{K}$ and $\mathrm{C}(4.5 \mathrm{~kJ} / \mathrm{mol})$, whereas on average the difference is $2.4 \mathrm{~kJ} / \mathrm{mol}$. The differences between data from intersecting sections are generally larger than uncertainties of integral enthalpy of mixing reported in Tables 2, 3, and 4, which do not exceed $0.9 \mathrm{~kJ} / \mathrm{mol}$. In any ternary system integral enthalpies of mixing depend on enthalpies of starting binary alloys. Literature integral enthalpies of mixing of $\mathrm{Pb}$-Sb alloys, as summarized in Ref 4, are close to each other within the margin of $0.2 \mathrm{~kJ} / \mathrm{mol}$. Whereas different sets of integral enthalpies of mixing of Li-Sb (Table 3 and Ref 7,8) as well as $\mathrm{Li}-\mathrm{Pb}^{[5,6]}$ alloys are close within the margin of $3 \mathrm{~kJ} / \mathrm{mol}$. It should be noted that values of starting points in the $\mathrm{Li}-\mathrm{Pb}$ and $\mathrm{Li}-\mathrm{Sb}$ systems used in the present study are generally more negative than those of other authors (within the $3 \mathrm{~kJ} / \mathrm{mol}$ margins), thus changing the starting points values would not improve the agreement of experimental sections near the points of intersection. Considering the magnitude of integral enthalpies of mixing (tens of $\mathrm{kJ} / \mathrm{mol}$ ) in the Li-Pb-Sb ternary and that they change strongly with composition, the differences between the experimental values of integral enthalpies of mixing near the points of intersection are acceptable, and it can be concluded that the data measured from different sides of Gibbs triangle are coherent.

Partial enthalpies of $\mathrm{Sb}$ measured from $\mathrm{Li}-\mathrm{Pb}$ side (sections A-F) jump suddenly from very negative values $(\sim-160 \mathrm{~kJ} / \mathrm{mol}$ for section $\mathrm{B}$, and $\sim-200 \mathrm{~kJ} / \mathrm{mol}$ for section $\mathrm{F}$ ) to positive ones at relatively low concentrations of $\mathrm{Sb}$. This is particularly well visible for sections B, C, D where two runs were performed, the second run with a substantially smaller increment of $\mathrm{Sb}$ concentration (Fig. 3a). The concentration range in which the jump occurs for each section corresponds to the position of integral enthalpy minima observed in Fig. 2(a). Such an abrupt increase in partial enthalpies of the added component was earlier observed in a number of liquid binary lithium alloys, such as $\mathrm{Li}-\mathrm{Pb}^{[5]}$ and $\mathrm{Li}-\mathrm{Sn},{ }^{[11]}$ when the second component was dropped to $\mathrm{Li}$ at temperatures close to melting temperature of the highest melting intermetallic 


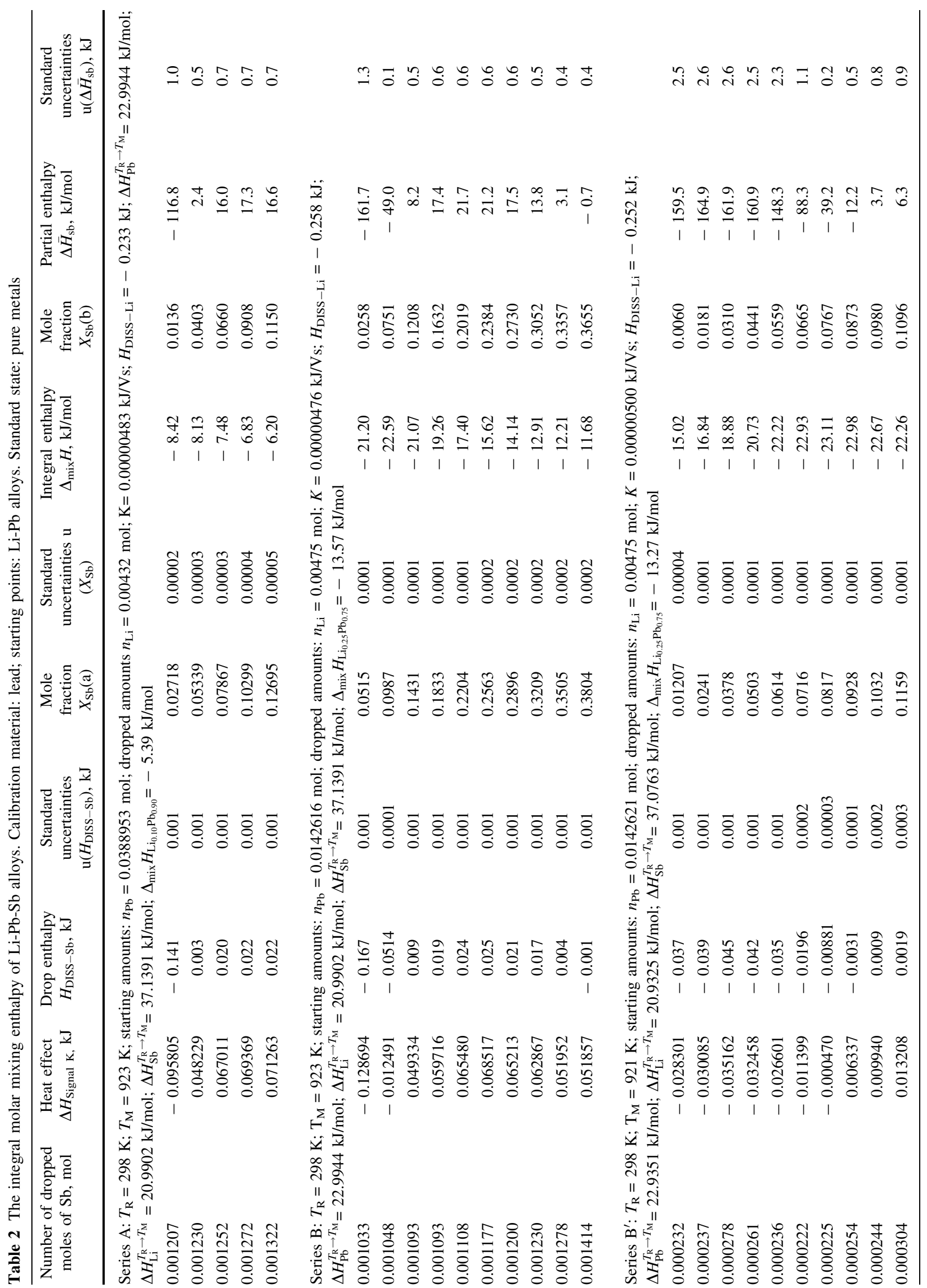




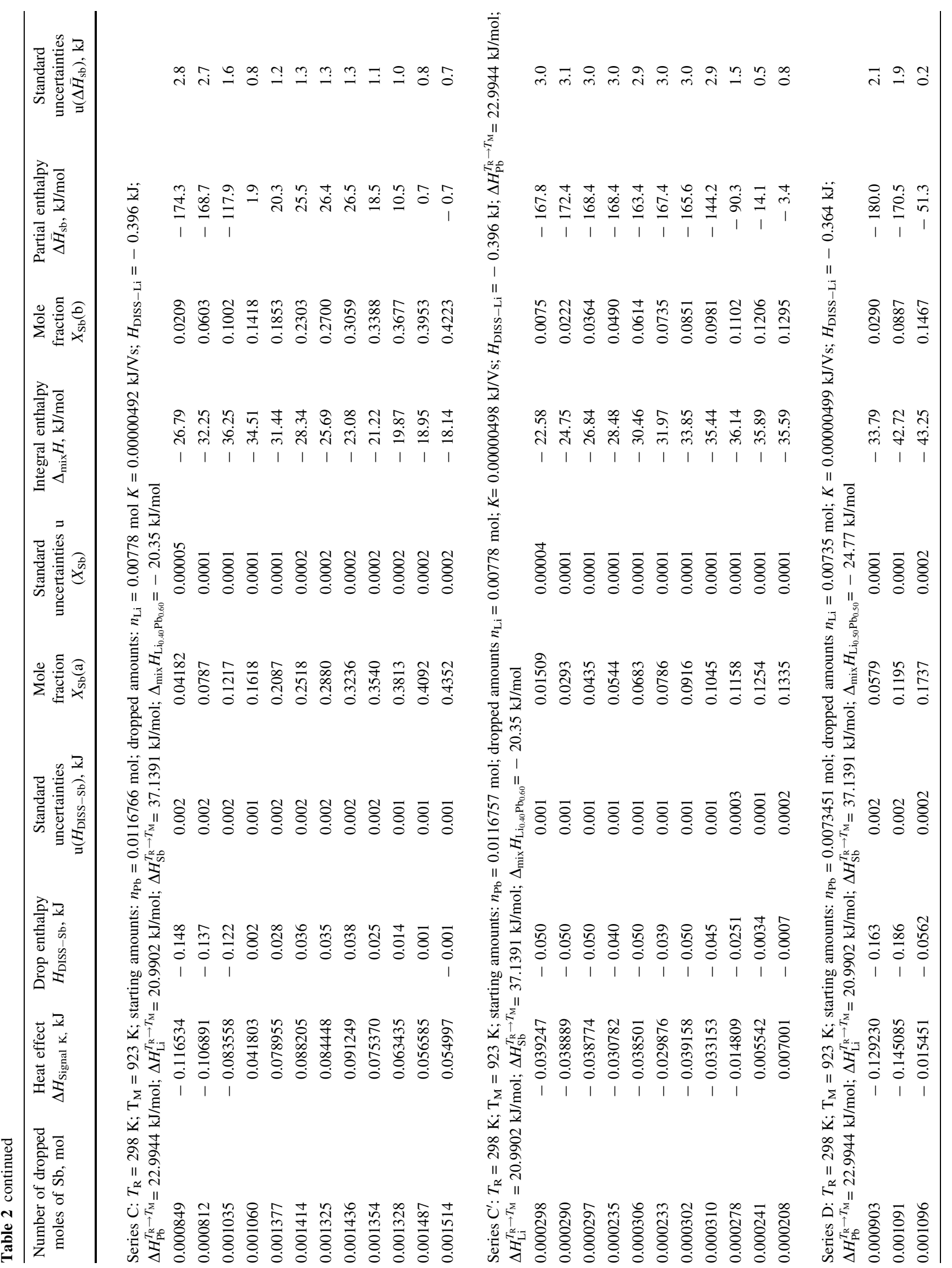




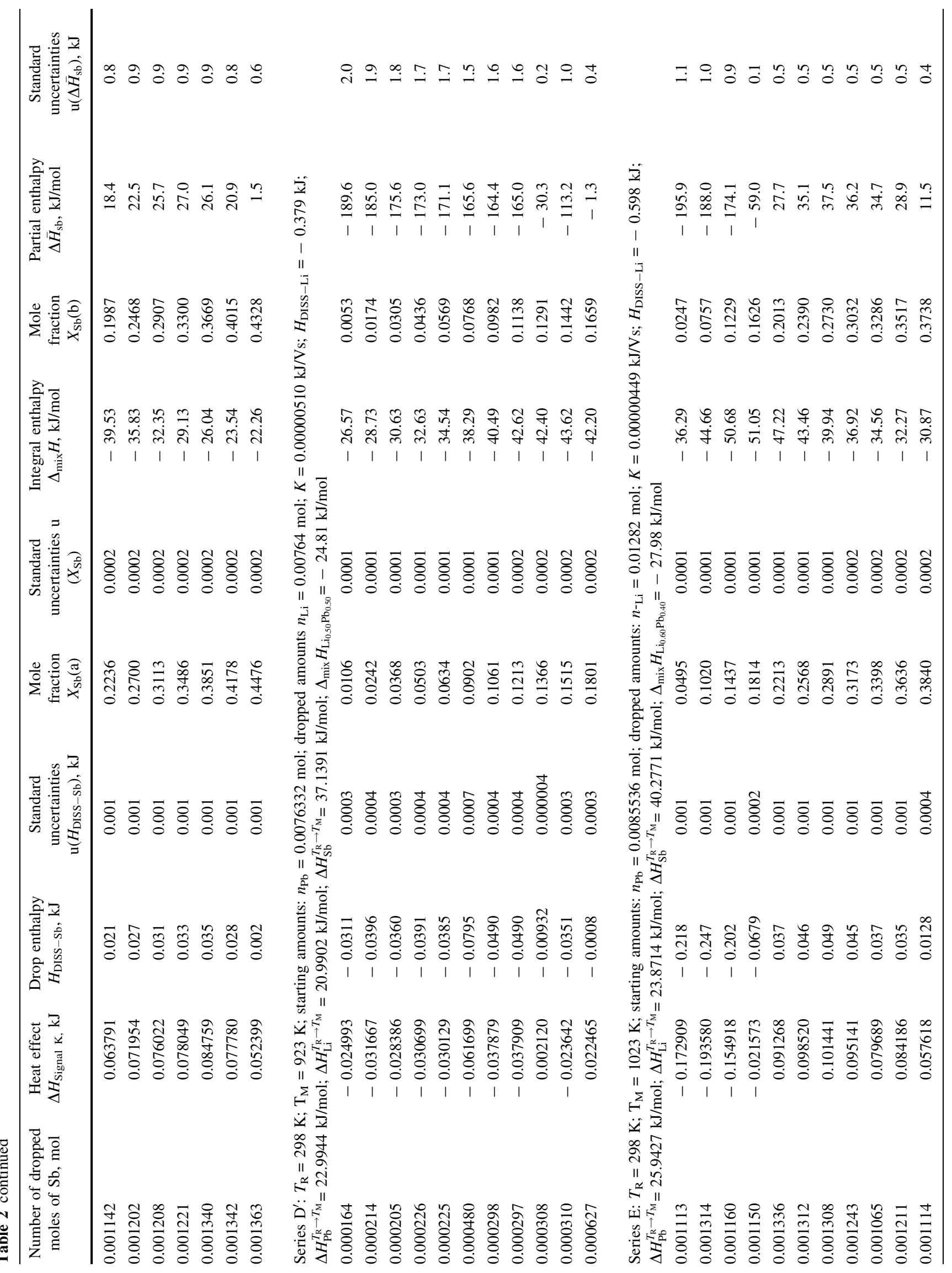




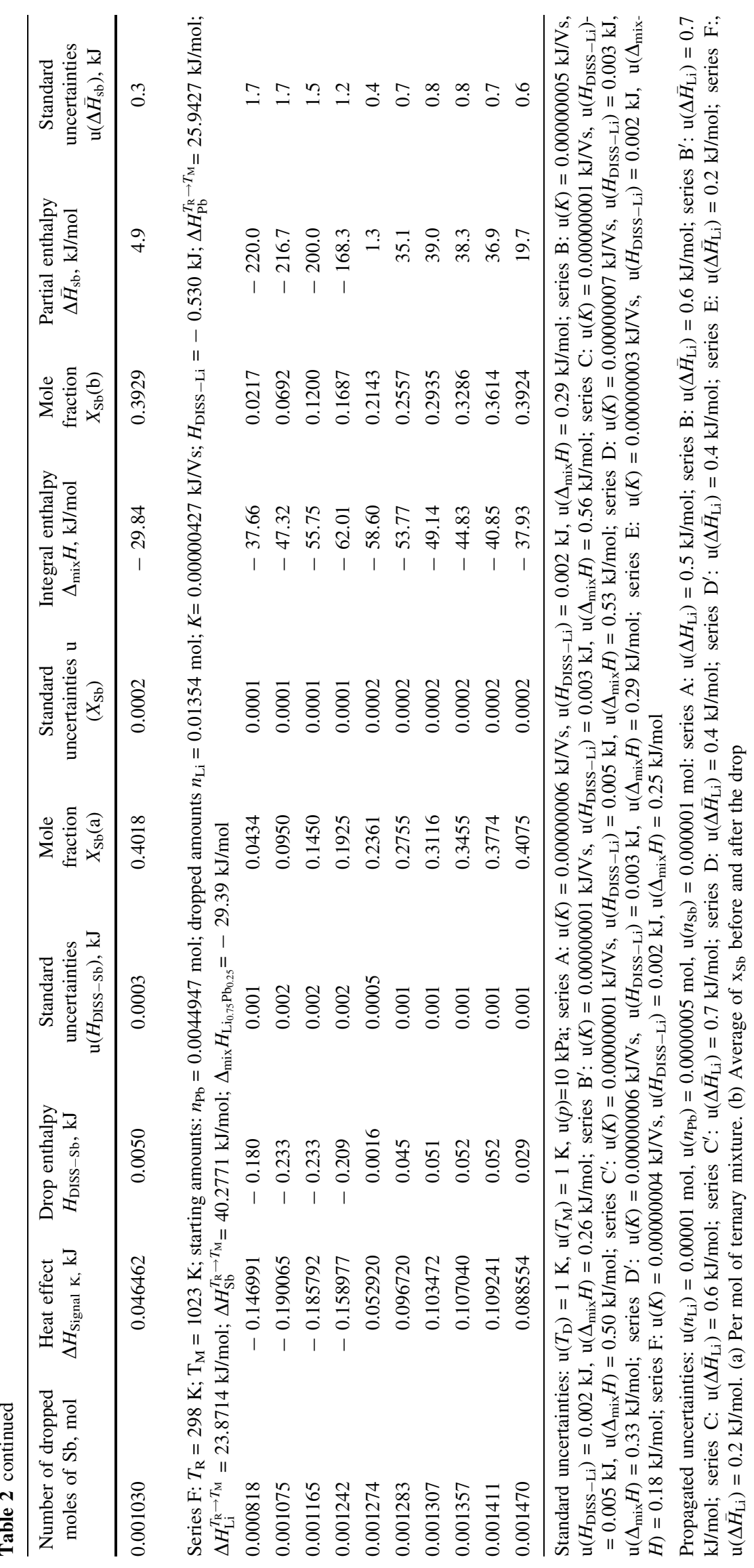




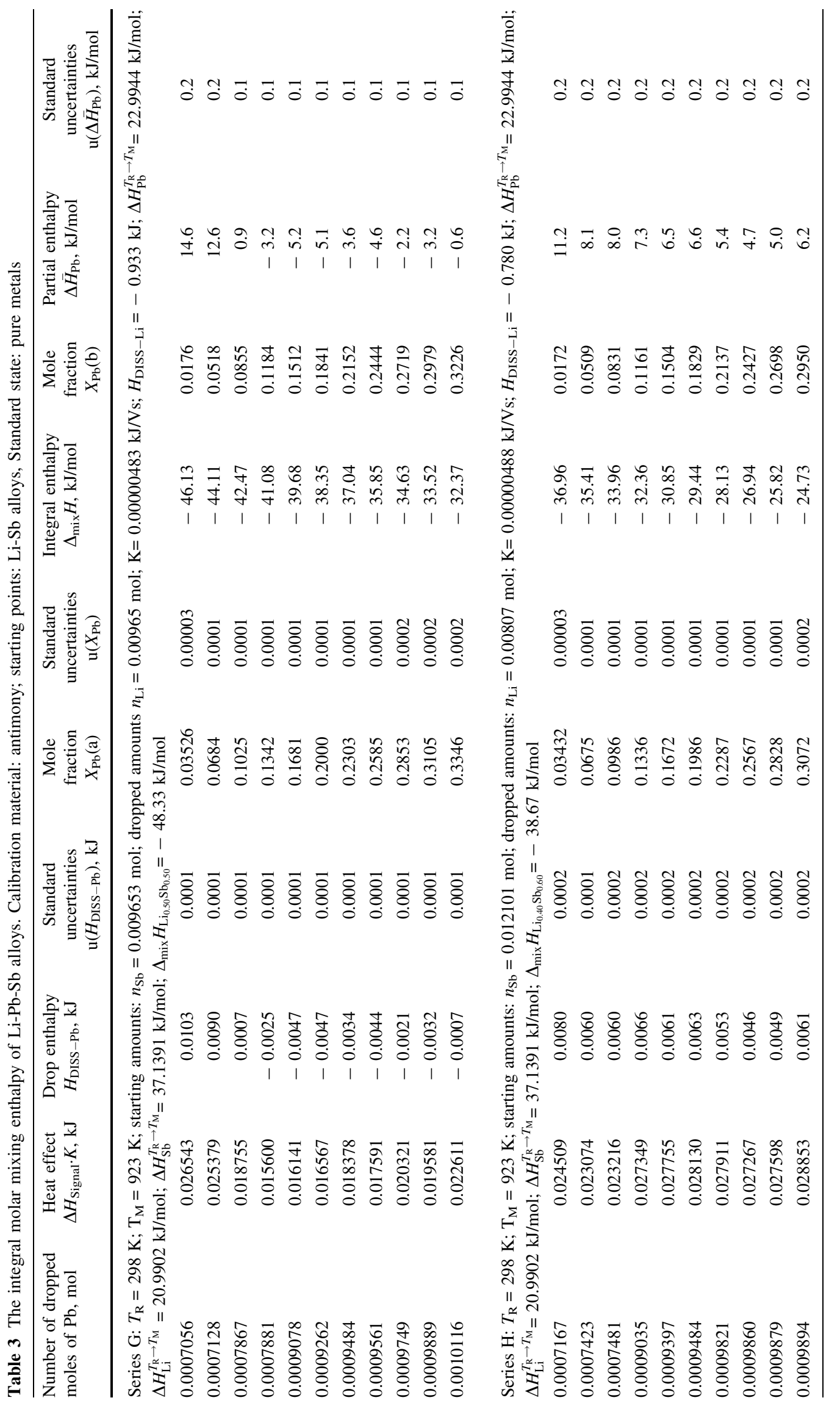




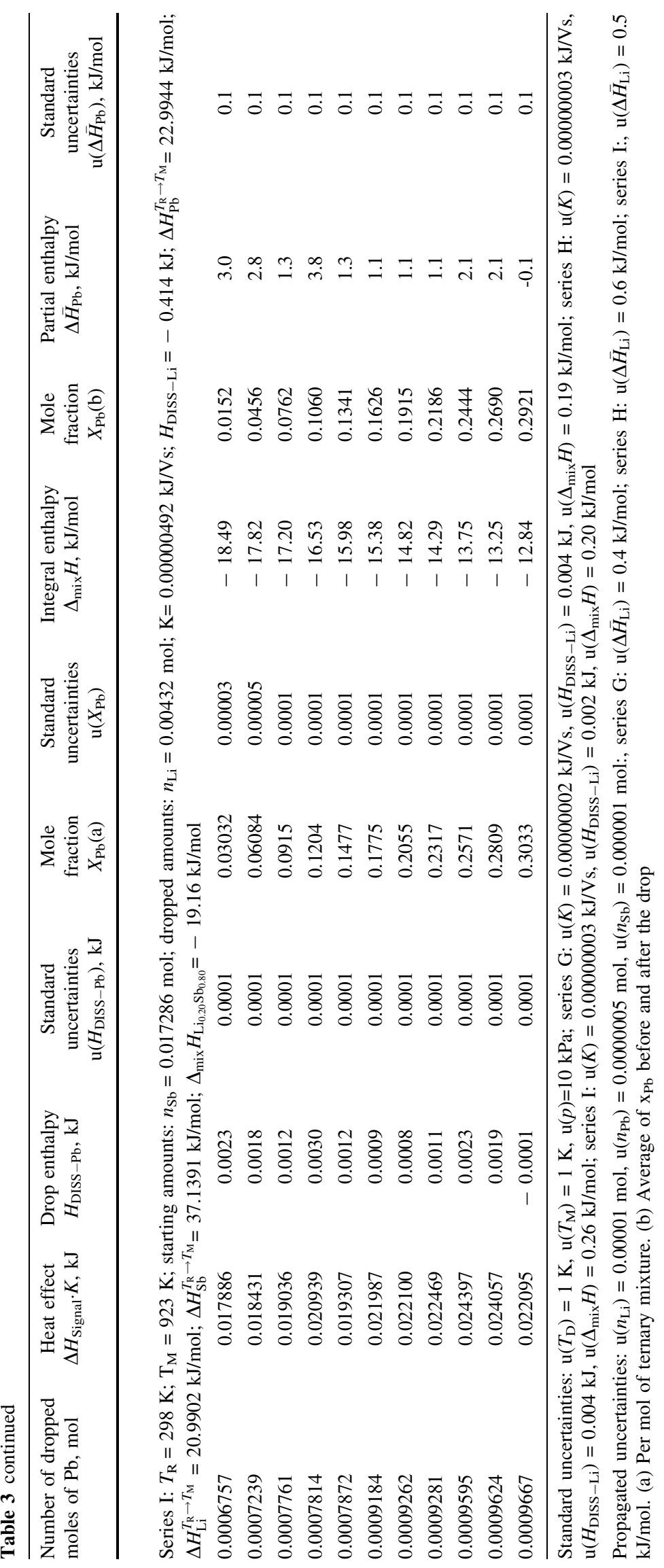


Table 4 The integral molar mixing enthalpy of Li-Pb-Sb alloys. Calibration material: lead; starting points: Pb-Sb alloys. Standard state: pure metals

\begin{tabular}{|c|c|c|c|c|c|c|c|c|c|}
\hline $\begin{array}{c}\text { Number of } \\
\text { dropped } \\
\text { moles of } \mathrm{Li} \text {, } \\
\text { mol }\end{array}$ & $\begin{array}{l}\text { Heat effect } \\
\Delta H_{\text {Signal }} K, \\
\text { kJ }\end{array}$ & $\begin{array}{c}\text { Drop } \\
\text { enthalpy } \\
H_{\text {DISS-Li }}, \\
\text { kJ }\end{array}$ & $\begin{array}{c}\text { Standard } \\
\text { uncertainties } \\
\mathrm{u}\left(H_{\text {DISS-Li }}\right), \\
\text { kJ }\end{array}$ & $\begin{array}{c}\text { Mole } \\
\text { fraction } \\
X_{\mathrm{Li}}(\mathrm{a})\end{array}$ & $\begin{array}{c}\text { Standard } \\
\text { uncertainties } \\
\mathrm{u}\left(X_{\mathrm{Li}}\right)\end{array}$ & $\begin{array}{c}\text { Integral } \\
\text { enthalpy } \\
\Delta_{\text {mix }} H, \\
\mathrm{~kJ} / \mathrm{mol}\end{array}$ & $\begin{array}{c}\text { Mole } \\
\text { fraction } \\
X_{\mathrm{Li}}(\mathrm{b})\end{array}$ & $\begin{array}{c}\text { Partial } \\
\text { enthalpy } \\
\Delta \bar{H}_{\mathrm{Li}}, \\
\mathrm{kJ} / \mathrm{mol}\end{array}$ & $\begin{array}{c}\text { Standard } \\
\text { uncertainties } \\
\mathrm{u}\left(\Delta \bar{H}_{\mathrm{Li}}\right) \\
\mathrm{kJ} / \mathrm{mol}\end{array}$ \\
\hline
\end{tabular}

Series J: $T_{R}=298 \mathrm{~K} ; \mathrm{T}_{\mathrm{M}}=923 \mathrm{~K}$; starting amounts: $n_{\mathrm{Pb}}=0.0061737 \mathrm{~mol}$; dropped amounts: $n_{\mathrm{Sb}}=0.018521 \mathrm{~mol} ; \mathrm{K}=0.00000483 \mathrm{~kJ} / \mathrm{Vs}$; $H_{\mathrm{DISS}-\mathrm{Pb}-\mathrm{Sb}}=-0.001 \mathrm{~kJ} ; \Delta H_{\mathrm{Pb}}^{T_{\mathrm{R}} \rightarrow T_{\mathrm{M}}}=22.9944 \mathrm{~kJ} / \mathrm{mol} ; \Delta H_{\mathrm{Li}}^{T_{\mathrm{R}} \rightarrow T_{\mathrm{M}}}=20.9902 \mathrm{~kJ} / \mathrm{mol} ; \Delta H_{\mathrm{Sb}}^{T_{\mathrm{R}} \rightarrow T_{\mathrm{M}}}=37.1391 \mathrm{~kJ} / \mathrm{mol} ;$

$\Delta_{\text {mix }} H_{\mathrm{Pb}_{0.25} \mathrm{Sb}_{0.75}}=-46.08 \mathrm{~J} / \mathrm{mol}$

$\begin{array}{llllllllll}0.005043 & -0.356581 & -0.462 & 0.005 & 0.1696 & 0.0004 & -15.57 & 0.0848 & -91.6 & 1.0 \\ 0.004754 & -0.340800 & -0.441 & 0.005 & 0.2840 & 0.0004 & -26.21 & 0.2268 & -92.8 & 1.0 \\ 0.004754 & -0.339886 & -0.440 & 0.005 & 0.3708 & 0.0004 & -34.25 & 0.3274 & -92.6 & 1.0 \\ 0.005475 & -0.490527 & -0.605 & 0.007 & 0.4478 & 0.0004 & -43.58 & 0.4093 & -110.5 & 1.3 \\ 0.008644 & -0.852695 & -1.034 & 0.012 & 0.5372 & 0.0003 & -55.90 & 0.4925 & -119.6 & 1.4\end{array}$

Series K: $T_{R}=298 \mathrm{~K} ; \mathrm{T}_{\mathrm{M}}=923 \mathrm{~K}$; starting amounts: $n_{\mathrm{Pb}}=0.0067379 \mathrm{~mol}$; dropped amounts $n_{\mathrm{Sb}}=0.006737 \mathrm{~mol} ; \mathrm{K}=0.00000487 \mathrm{~kJ} / \mathrm{Vs}$; $H_{\mathrm{DISS}-\mathrm{Pb}-\mathrm{Sb}}=-0.001 \mathrm{~kJ} ; \Delta H_{\mathrm{Pb}}^{T_{\mathrm{R}} \rightarrow T_{\mathrm{M}}}=22.9944 \mathrm{~kJ} / \mathrm{mol} ; \Delta H_{\mathrm{Li}}^{T_{\mathrm{R}} \rightarrow T_{\mathrm{M}}}=20.9902 \mathrm{~kJ} / \mathrm{mol} ; \Delta H_{\mathrm{Sb}}^{T_{\mathrm{R}} \rightarrow T_{\mathrm{M}}}=37.1391 \mathrm{~kJ} / \mathrm{mol}$; $\Delta_{\mathrm{mix}} H_{\mathrm{Pb}_{0.50} \mathrm{Sb}_{0.50}}=-61.44 \mathrm{~J} / \mathrm{mol}$

$\begin{array}{lllllllllr}0.004610 & -0.349702 & -0.446 & 0.003 & 0.2549 & 0.0006 & -24.72 & 0.1275 & -96.7 & 0.6 \\ 0.005187 & -0.470450 & -0.579 & 0.003 & 0.4210 & 0.0005 & -44.09 & 0.3380 & -111.6 & 0.6 \\ 0.004898 & -0.451660 & -0.554 & 0.003 & 0.5217 & 0.0004 & -56.09 & 0.4714 & -113.1 & 0.7 \\ 0.004898 & -0.452015 & -0.555 & 0.003 & 0.5925 & 0.0004 & -64.56 & 0.5571 & -113.3 & 0.7 \\ 0.003890 & -0.173252 & -0.255 & 0.001 & 0.6354 & 0.0003 & -64.67 & 0.6140 & -65.6 & 0.4\end{array}$

Series L: $T_{R}=298 \mathrm{~K} ; \mathrm{T}_{\mathrm{M}}=923 \mathrm{~K}$; starting amounts: $n_{\mathrm{Pb}}=0.0128962 \mathrm{~mol}$; dropped amounts: $n_{\mathrm{Sb}}=0.004299 \mathrm{~mol} ; \mathrm{K}=0.00000485 \mathrm{~kJ} / \mathrm{Vs}$; $H_{\text {DISS }-\mathrm{Pb}-\mathrm{Sb}}=-0.001 \mathrm{~kJ} ; \Delta H_{\mathrm{Pb}}^{T_{\mathrm{R}} \rightarrow T_{\mathrm{M}}}=22.9944 \mathrm{~kJ} / \mathrm{mol} ; \Delta H_{\mathrm{Li}}^{T_{\mathrm{R}} \rightarrow T_{\mathrm{M}}}=20.9902 \mathrm{~kJ} / \mathrm{mol} ; \Delta H_{\mathrm{Sb}}^{T_{\mathrm{R}} \rightarrow T_{\mathrm{M}}}=37.1391 \mathrm{~kJ} / \mathrm{mol}$; $\Delta_{\text {mix }} H_{\mathrm{Pb}_{0.75} \mathrm{Sb}_{0.25}}=-46.08 \mathrm{~J} / \mathrm{mol}$

$\begin{array}{lrllllllrr}0.004466 & -0.329073 & -0.423 & 0.013 & 0.2062 & 0.0005 & -19.62 & 0.1031 & -94.7 & 2.8 \\ 0.004610 & -0.406989 & -0.504 & 0.016 & 0.3455 & 0.0005 & -35.35 & 0.2759 & -109.3 & 3.3 \\ 0.004610 & -0.368900 & -0.466 & 0.014 & 0.4432 & 0.0005 & -45.15 & 0.3944 & -101.0 & 3.0 \\ 0.004610 & -0.140653 & -0.237 & 0.006 & 0.5155 & 0.0004 & -45.98 & 0.4794 & -51.5 \\ 0.004898 & 0.086352 & -0.016 & 0.003 & 0.5743 & 0.0004 & -40.81 & 0.5449 & -3.4 & 0.7\end{array}$

Standard uncertainties: $\mathrm{u}\left(T_{\mathrm{D}}\right)=1 \mathrm{~K}, \mathrm{u}\left(T_{\mathrm{M}}\right)=1 \mathrm{~K}, \mathrm{u}(p)=10 \mathrm{kPa}$, series $\mathrm{J}$ : $\mathrm{u}(K)=0.00000007 \mathrm{~kJ} / \mathrm{Vs}, \mathrm{u}\left(\Delta_{\text {mix }} H\right)=0.34 \mathrm{~kJ} / \mathrm{mol} ;$ series $\mathrm{K}$ : $\mathrm{u}(K)=0,00000003 \mathrm{~kJ} / \mathrm{Vs}, \mathrm{u}\left(\Delta_{\text {mix }} H\right)=0.25 \mathrm{~kJ} / \mathrm{mol}$; series L: $\mathrm{u}(K)=0.00000002 \mathrm{~kJ} / \mathrm{Vs}, \mathrm{u}\left(\Delta_{\text {mix }} H\right)=0.88 \mathrm{~kJ} / \mathrm{mol}$

Propagated uncertainties: $\mathrm{u}\left(n_{\mathrm{Li}}\right)=0.00001 \mathrm{~mol}, \mathrm{u}\left(n_{\mathrm{Pb}}\right)=0.0000005 \mathrm{~mol}, \mathrm{u}\left(n_{\mathrm{Sb}}\right)=0.000001 \mathrm{~mol}$. (a) Per mol of ternary mixture. (b) Average of $\mathrm{x}_{\mathrm{Li}}$ before and after the drop

phase. As long as associates $\left(\mathrm{Li}_{4} \mathrm{~Pb}\right.$ in Ref 12 and $\mathrm{Li}_{4} \mathrm{Sn}$ in Ref 13) are formed in the liquid phase partial enthalpies are low, sharp increase in partial enthalpies means that associates are not formed anymore and no longer contribute to partial enthalpies, as a result integral mixing enthalpies start to increase. Also in the $\mathrm{Li}-\mathrm{Sb}$ system, the $\mathrm{Li}_{3} \mathrm{Sb}$ associate is included in thermodynamic description of LiSb liquid phase. ${ }^{[8]}$ On the other hand, partial enthalpies of $\mathrm{Pb}$ measured from Li-Sb side (Fig. 3b) do not show similar jumps up, instead, for sections $\mathrm{H}$, I they change rather monotonously (regardless some scatter) in the concentration range studied. Only in the case of section $G$ there is $\sim 16 \mathrm{~kJ} / \mathrm{mol}$ decrease of partial enthalpies between 0.05 and $0.12 \mathrm{~mol}$ fraction $\mathrm{Pb}$. Changes of partial enthalpies of $\mathrm{Li}$, measured from $\mathrm{Pb}-\mathrm{Sb}$ side (Fig. 3c), with Li concentration are difficult to track, because of very big concentration step between individual drops. Nevertheless, for section $\mathrm{L}$ ( $\mathrm{Pb}$ to $\mathrm{Sb}$ molar ratio equal to 3 ) it can be noticed that partial enthalpy of $\mathrm{Li}$ increases after concentration of Li exceeded 0.44 mol fraction, whereas for section $\mathrm{K}(\mathrm{Pb}$ to $\mathrm{Sb}$ ratio equal to 1) partial enthalpy of $\mathrm{Li}$ increases above 0.6 mol fraction $\mathrm{Li}$.

The observed variation of integral enthalpies of mixing of ternary Li-Pb-Sb alloys (Fig. 2) can be explained by 

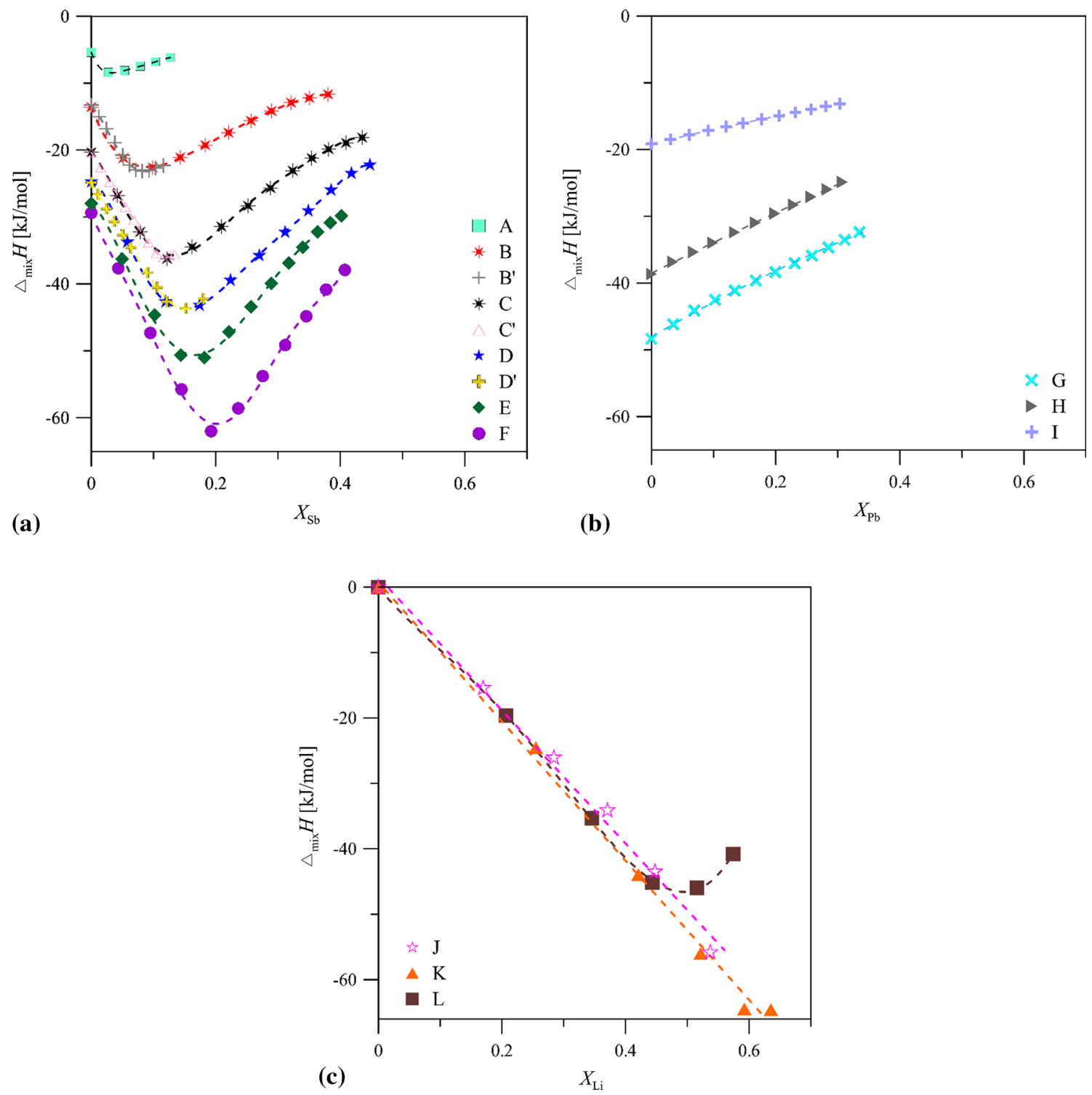

Fig. 2 The integral molar mixing enthalpy of Li-Pb-Sb alloys (points) measured by dropping (a) Sb to Li-Pb alloys at 923 and $1023 \mathrm{~K}$, (b) $\mathrm{Pb}$ to $\mathrm{Li}-\mathrm{Sb}$ alloys at $923 \mathrm{~K}$, (c) Li to $\mathrm{Pb}-\mathrm{Sb}$ alloys at $923 \mathrm{~K}$ (dashed lines as guide for an eye only)

differences in integral enthalpies of mixing of limiting binary systems. Integral enthalpy of mixing of liquid $\mathrm{Pb}-\mathrm{Sb}$ alloys is close to zero, which is characteristic for a system showing near ideal behavior. As concentration of $\mathrm{Li}$ increases, integral enthalpy of mixing decreases similarly to $\mathrm{Li}-\mathrm{Pb}$ and $\mathrm{Li}-\mathrm{Sb}$ systems, as $\mathrm{Li}$ interacts strongly with $\mathrm{Pb}$ and $\mathrm{Sb}$. The minimum of integral mixing enthalpy in ternary $\mathrm{Li}-\mathrm{Pb}-\mathrm{Sb}$ alloys $(\sim-63 \mathrm{~kJ} / \mathrm{mol})$ is much deeper than the minimum in the $\mathrm{Li}-\mathrm{Pb}$ system $(\sim-29 \mathrm{~kJ} / \mathrm{mol}),{ }^{[5]}$ which indicates that that the interactions between $\mathrm{Li}$ and $\mathrm{Sb}$ are much stronger than between $\mathrm{Li}$ and $\mathrm{Pb}$, and dominate in the ternary $\mathrm{Li}-\mathrm{Pb}-\mathrm{Sb}$ alloys.

This does not mean that all of the reported enthalpies of mixing of ternary $\mathrm{Li}-\mathrm{Pb}-\mathrm{Sb}$ alloys represent fully liquid concentrations range. The present measurements were conducted at 923 and $1023 \mathrm{~K}$ to ensure that starting alloys for each measured section were fully liquid at the beginning of measurement. It should be noted, though, that in the $\mathrm{Li}-\mathrm{Sb}$ system in the concentration range of 0.58 and 
Table 5 The values of the integral enthalpies of mixing near the selected points of intersection of series presented in Fig. 1

\begin{tabular}{|c|c|c|c|c|c|}
\hline \multirow[t]{2}{*}{ Intersection } & \multicolumn{3}{|c|}{ Coordinates of point of intersection } & \multicolumn{2}{|c|}{ Experimental integral molar mixing enthalpy, $\mathrm{kJ} / \mathrm{mol}$} \\
\hline & $X_{\mathrm{Li}}$ & $X_{\mathrm{Sb}}$ & $X_{\mathrm{Pb}}$ & & \\
\hline GE & 0.375 & 0.375 & 0.250 & $\begin{array}{l}G \\
-32.3\end{array}$ & $\begin{array}{l}E \\
-30.9\end{array}$ \\
\hline $\mathrm{HD}$ & 0.286 & 0.428 & 0.286 & $\begin{array}{l}\mathrm{H} \\
-25.8\end{array}$ & $\begin{array}{l}\mathrm{D} \\
-23.5\end{array}$ \\
\hline $\mathrm{JF}$ & 0.429 & 0.428 & 0.143 & $\begin{array}{l}\text { J } \\
-43.6\end{array}$ & $\begin{array}{l}F \\
-37.9\end{array}$ \\
\hline $\mathrm{JI}$ & 0.158 & 0.631 & 0.211 & $\begin{array}{l}\text { J } \\
-15.6\end{array}$ & $\begin{array}{l}\text { I } \\
-14.8\end{array}$ \\
\hline $\mathrm{KC}$ & 0.250 & 0.375 & 0.375 & $\begin{array}{l}\mathrm{K} \\
-24.7\end{array}$ & $\begin{array}{l}\text { C } \\
-19.9\end{array}$ \\
\hline $\mathrm{KE}$ & 0.428 & 0.286 & 0.286 & $\begin{array}{l}\mathrm{K} \\
-44.1\end{array}$ & $\begin{array}{l}E \\
-39.9\end{array}$ \\
\hline $\mathrm{KF}$ & 0.6012 & 0.1994 & 0.1994 & $\begin{array}{l}\mathrm{K} \\
-64.6\end{array}$ & $\begin{array}{l}F \\
-62.0\end{array}$ \\
\hline LB & 0.200 & 0.200 & 0.600 & $\begin{array}{l}\mathrm{L} \\
-19.6\end{array}$ & $\begin{array}{l}\text { B } \\
-19.3\end{array}$ \\
\hline $\mathrm{LC}$ & 0.333 & 0.167 & 0.500 & $\begin{array}{l}\mathrm{L} \\
-35.4\end{array}$ & $\begin{array}{l}\mathrm{C} \\
-34.5\end{array}$ \\
\hline LD & 0.427 & 0.143 & 0.427 & $\begin{array}{l}\mathrm{L} \\
-45.2\end{array}$ & $\begin{array}{l}D \\
-42.7\end{array}$ \\
\hline LE & 0.529 & 0.118 & 0.353 & $\begin{array}{l}\text { L } \\
-46.0\end{array}$ & $\begin{array}{l}\mathrm{E} \\
-44.7\end{array}$ \\
\hline
\end{tabular}

0.97 mol fraction of $\mathrm{Li}$ the liquidus is much higher than $1023 \mathrm{~K}$, in particular at $0.75 \mathrm{~mol}$ fraction $\mathrm{Li}$ it reaches $1580 \mathrm{~K}{ }^{[8]}$ Therefore it can be expected that at $923 \mathrm{~K}$ the semi-liquid concentration range extends deep into the ternary Li-Pb-Sb alloys. The minima of integral enthalpies of mixing measured by dropping $\mathrm{Sb}$ from $\mathrm{Li}-\mathrm{Pb}$ side and $\mathrm{Li}$ from $\mathrm{Pb}-\mathrm{Sb}$ side (sections $\mathrm{L}, \mathrm{K}$ ) are roughly on one line connecting $\mathrm{Li}_{3} \mathrm{Sb}$ and $\mathrm{Pb}$-corner of composition triangle. Possibly, when $\mathrm{Sb}$ is added to liquid Li-Pb alloys then solid $\mathrm{Li}_{3} \mathrm{Sb}$ precipitates and heat effects from precipitation further decrease integral enthalpies. Once concentration of $\mathrm{Sb}$ crosses the abovementioned line and no more $\mathrm{Li}_{3} \mathrm{Sb}$ precipitates the integral enthalpies start to increase. This is similar to what was reported in the Li-Sb system, ${ }^{[8]}$ and well explains the sharp increase of partial enthalpies discussed above.

Because there is no phase diagram of the $\mathrm{Li}-\mathrm{Pb}-\mathrm{Sb}$ system it is not possible to say what the range of homogenous liquid at $923 \mathrm{~K}$ should be. Calorimetric measurements make it possible to detect liquidus limit, based on kinks of integral enthalpies and discontinuity of partial enthalpies with a concentration of added component, ${ }^{[14]}$ accompanying crossing from homogenous liquid into two-phase concentration range. It helps if the data points are dense (concentration change between the points is small) otherwise any change of trend in integral enthalpies can go unnoticed. However, in the case of enthalpies measured by dropping $\mathrm{Li}$ from $\mathrm{Pb}-\mathrm{Sb}$ side (series L, K, J) large concentration step between the drops of $\mathrm{Li}$ makes the data difficult to interpret. No obvious change of slope of integral enthalpies of mixing measured by dropping $\mathrm{Pb}$ (series $\mathrm{G}, \mathrm{H}, \mathrm{I}$ ) is observed. It is similar in the case of integral enthalpies measured by dropping $\mathrm{Sb}$ from Li-Pb side (series A-F), except for minima explained above. Based on the gathered data it is not possible to give even tentative liquidus position. Nevertheless, it can be assumed that ternary $\mathrm{Li}-\mathrm{Pb}-\mathrm{Sb}$ alloys of low $\mathrm{Li}$ content (i.e. below $0.4 \mathrm{~mol}$ fraction $\mathrm{Li}$ ) in Sb-rich corner are fully liquid at $923 \mathrm{~K}$. 

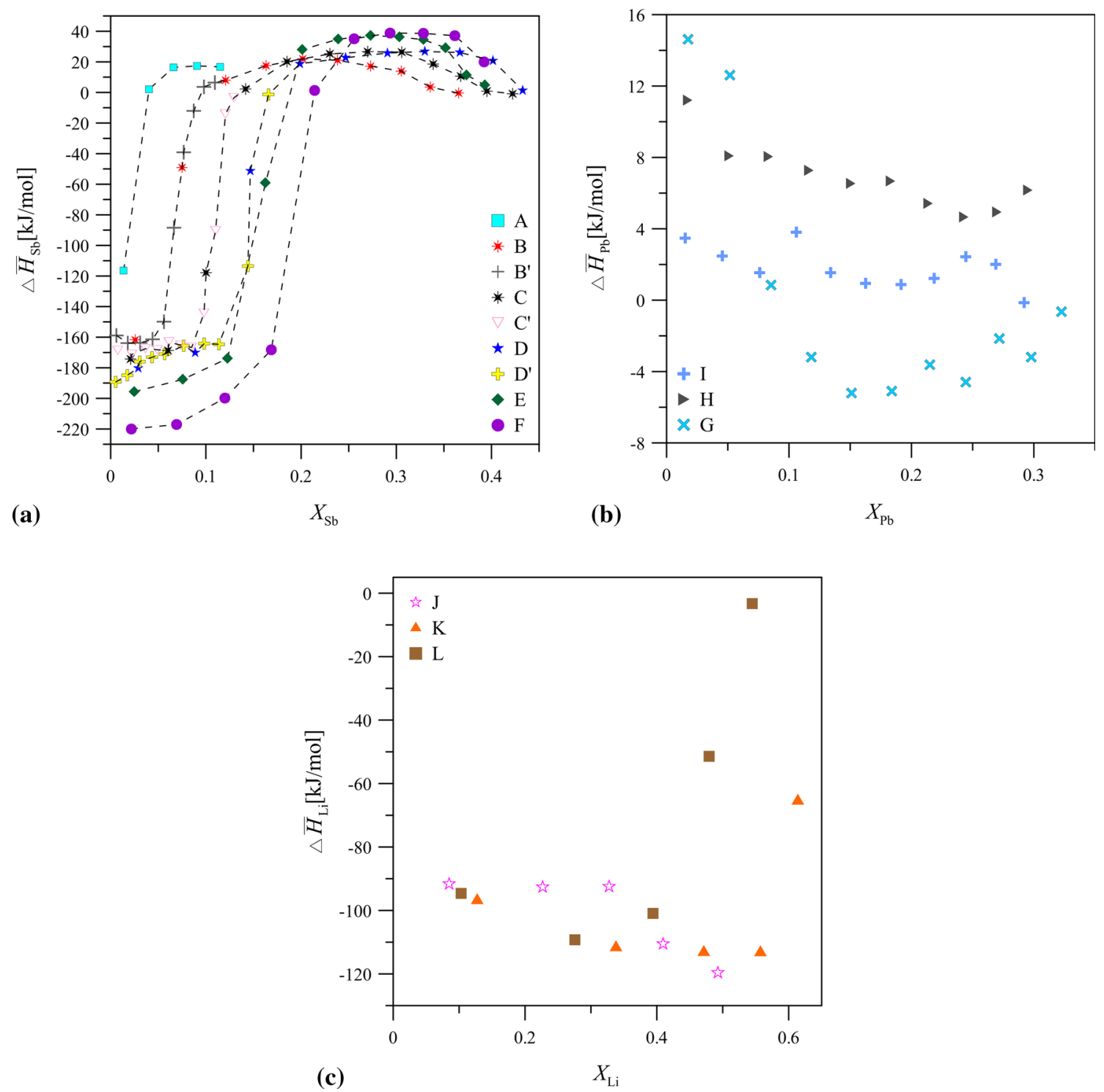

Fig. 3 Partial enthalpies of (a) Sb at 923 and $1023 \mathrm{~K}$, (b) $\mathrm{Pb}$ at $923 \mathrm{~K}$, (c) Li at $923 \mathrm{~K}$ in Li-Pb-Sb system

\section{Conclusion}

Calorimetric measurements of the mixing enthalpies of Li$\mathrm{Pb}-\mathrm{Sb}$ alloys were performed at 923 and $1023 \mathrm{~K}$ over broad composition range. Twelve sections were studied by $\mathrm{Li}, \mathrm{Pb}$ and $\mathrm{Sb}$ drop dissolution calorimetry. The integral enthalpies of mixing of $\mathrm{Li}-\mathrm{Pb}-\mathrm{Sb}$ alloys were negative in the entire composition range studied. The integral enthalpies dependence on composition in the $\mathrm{Li}-\mathrm{Pb}-\mathrm{Sb}$ ternary alloys can be explained by strong interactions between $\mathrm{Li}$ and $\mathrm{Sb}$ in the Li-Sb binary, which dominate in the ternary alloys.

Acknowledgments Investigations were performed thanks to the statutory funds of Institute of Metallurgy and Materials Science, Polish Academy of Sciences (Z-9/1).
Open Access This article is distributed under the terms of the Creative Commons Attribution 4.0 International License (http://crea tivecommons.org/licenses/by/4.0/), which permits unrestricted use, distribution, and reproduction in any medium, provided you give appropriate credit to the original author(s) and the source, provide a link to the Creative Commons license, and indicate if changes were made.

Author Contributions ST, AD carried out enthalpy measurements, ST, PF analyzed results, PF had the idea for this project, wrote the manuscript.

\section{References}

1. D.J. Bradwell, H. Kim, A.H.C. Sirk, and D.R. Sadoway, Magnesium-Antimony Liquid Metal Battery for Stationary Energy Storage, J. Am. Chem. Soc., 2012, 134(4), p 1895-1897 
2. H. Kim, D.A. Boysen, J.M. Newhouse, B.L. Spatocco, B. Chung, P.J. Burke, D.J. Bradwell, K.J. Alina, A. Tomaszowska, K. Wang, W. Wei, L.A. Ortiz, S.A. Barriga, S.M. Poizeau, and D.R. Sadoway, Liquid metal Batteries: Past, Present, and Future, Chem. Rev., 2013, 113, p 2075-2099

3. K. Wang, K. Jiang, B. Chung, W. Ouchi, P.J. Burke, D.A. Boysen, D.J. Bradwell, H. Kim, U. Muecke, and D.R. Sadoway, Lithium-Antimony-Lead Liquid Metal Battery for Grid-Level Energy Storage, Nature, 2014, 514(7522), p 348-350

4. W. Gierlotka, C. Lee, P. Chumpanaya, M.A. Rahman, and T.-N. Ko, Thermodynamic Re-Optimization of the Binary Pb-Sb System, J. Phase Equilib. Diffus., 2013, 34, p 421-424

5. B. Predel and G. Oehme, Calorimetric Investigation of Liquid LiPb-Alloys, Z. Metallkd., 1979, 70, p 450-453, in German

6. S. Terlicka, A. Dębski, and W. Gąsior, W, Thermodynamic Properties of Li-Pb system, J. Mol. Liq., 2018, 249, p 6672

7. S. Terlicka, A. Dębski, and P. Fima, Enthalpy of Formation of $\mathrm{Li}_{2} \mathrm{Sb}$ and $\mathrm{Li}_{3} \mathrm{Sb}$ and Mixing Enthalpy of Liquid Li-Sb Alloys, $J$. Alloy. Compd., 2017, 673, p 272-277
8. D. Li, A. Beutl, H. Flandorfer, and D.M. Cupid, The Li-Sb Phase Diagram Part II: Calorimetry and Thermodynamic Assessment, $J$. Alloy. Compd., 2017, 701, p 186-199

9. B. Predel, Crystallographic and Thermodynamic Data of Binary Alloys Pu-Re...Zn-Zr, in: The Landolt-Börnstein Phase Equlibria, IV-5 J, Springer Materials, Germany, 1998.

10. A.T. Dinsdale, SGTE Data for Pure Elements, Calphad, 1991, 15, p 317-425

11. S. Furtauer, E. Tserenjav, A. Yakymovych, and H. Flandorfer, Calorimetric Studies of $\mathrm{Cu}-\mathrm{Li}, \mathrm{Li}-\mathrm{Sn}$, and $\mathrm{Cu}-\mathrm{Li}-\mathrm{Sn}, J$. Chem. Thermodyn., 2013, 61, p 105-116

12. C. Zhou, C. Guo, C. Li, and Z. Du, Thermodynamic Optimization of the Li-Pb System Aided by First-Principles Calculations, $J$. Nucl. Mater., 2016, 477, p 95-101

13. D. Li, S. Furtauer, H. Flandorfer, and D.M. Cupid, Thermodynamic Assessment and Experimental Investigation of the Li-Sn System, Calphad, 2014, 47, p 181-195

14. Y. Plevachuk, A. Yakymovych, S. Furtauer, H. Ipser, and H. Flandorfer, The Enthalpies of Mixing of Liquid Ni-Sn-Zn Alloys, J. Phase Equilib. Diff., 2014, 35(4), p 359-368 